\title{
Characteristics of precipitating energetic electron fluxes relative to the plasmapause
}

\author{
Ian C. Whittaker, ${ }^{1}$ Mark A. Clilverd, ${ }^{2}$ Craig J. Rodger ${ }^{1}$
}

\begin{abstract}
We perform modeling of precipitating electrons from the Earth's radiation belts, based on observations from the POES satellite constellation. Superposed epoch analysis is performed on precipitating electron observations for the 13 year period of 1999 to 2012 in two MLT sectors. We assume the precipitation is due to wave particle interaction and our two MLT sectors focus on chorus (outside the plasmapause) and plasmapspheric hiss (inside the plasmapause) waves. We generate models which reproduce the chorus observations for $>30 \mathrm{keV}$ precipitating electron flux as well as fitted spectral index, allowing a full integral energy reproduction. The precipitating flux inside the plasmapause is dependent upon the particle energy, with our data resolution the precipitation is only visible in the $>300 \mathrm{keV}$ and P6 (relativistic electrons) channels of the flux detection instrument. The relative strengths of the wave particle interactions show that chorus precipitation has a stronger effect by a factor of 4.5.
\end{abstract}

\section{Introduction}

Energetic electron precipitation (EEP), which is strongest during geomagnetic storms, is of great interest to radiation belt and atmospheric scientists. The particle energy determines the altitude in the atmosphere at which the majority of its energy is deposited [e.g., Turunen et al., 2009, Fig.3]. Electrons with energies $\sim 100 \mathrm{keV}$ cause peak ionization changes at $\sim 80 \mathrm{~km}$ altitude while $\sim 1 \mathrm{MeV}$ electron energy peaks at $\sim 62 \mathrm{~km}$ altitude. This has major implications for atmospheric chemistry as precipitating charged particles produce odd nitrogen $\left(\mathrm{NO}_{x}\right.$ [Newnham et al., 2011] ) and odd hydrogen $\left(\mathrm{HO}_{x}\right.$ [Verronen et al., 2011]) in the Earth's atmosphere. These odd particles can then catalytically destroy ozone due to their longer lifetime at these altitudes [Solomon, Crutzen and Roble, 1982; Brasseur and Solomon, 2005; Verronen et al., 2013] and have been linked to variability in surface climate [Seppälä et al., 2013]. In particular, Andersson et al. [2012] reported experimental evidence of electron precipitation producing odd hydrogen changes, during geomagnetic storms, stretching over the altitude range of $\sim 52$ to $82 \mathrm{~km}$, corresponding to electrons from $\sim 100 \mathrm{keV}$ to $\sim 3 \mathrm{MeV}$. These authors recently showed that atmospheric $\mathrm{HO}_{x}$ increases during geomagnetic storms at atmospheric locations under the radiation belts [Andersson et al., 2014].

Wave-particle interactions can cause pitch angle [Lakhina et al., 2010] and energy [Meredith et al., 2002] diffusion. For a recent review on wave-particle interaction, see Thorne [2010]. In the VLF range one important type of wave is whistler-mode chorus, while in the ULF range attention tends to focus on EMIC (ElectroMagnetic Ion Cyclotron) waves [Horne and Thorne, 1998]. Chorus is in the frequency range of a few hundred $\mathrm{Hz}$ to several $\mathrm{kHz}$ [Helliwell, 1969] and occurs in the morning MLT region outside the plasmapause [Summers, Thorne and Xiao, 1998]. There

\footnotetext{
${ }^{1}$ Department of Physics, University of Otago, Dunedin, New Zealand.

${ }^{2}$ British Antarctic Survey (NERC), Cambridge, UK.
}

Copyright 2014 by the American Geophysical Union. $0148-0227 / 14 / \$ 9.00$ have been many studies which have linked chorus waves to intense energetic electron precipitation [e.g. Hikishima, Omura and Summers, 2010; Lam et al., 2010; Meredith et al., 2011], as expected from the strong wave amplitudes. Plasmaspheric hiss occurs in the inner magnetosphere over a band between $100 \mathrm{~Hz}$ and $2 \mathrm{kHz}$ [Summers, et al., 2008]. Hiss induced electron precipitation has been shown to be responsible for the formation of the slot region between the inner and outer radiation belts $[$ Lyons and Thorne, 1973]. Long-lasting plasmaspheric hiss-driven precipitation has been monitored from the ground [Rodger et al., 2007], and shown to be able to produce significant ozone depletions [Rodger et al., 2010a].

It has long been recognized that there is a link between the dynamical plasmapause location and the trapped fluxes in the outer radiation belt. Observations of relativistic electrons from SAMPEX showed that over times periods of weeks to months the plasmapause location was a good indication of the inner edge of the outer radiation belt [ $\mathrm{Li}$ et al., 2006]. This correlation demonstrates how the differing wave activity inside and outside the plasmapause strongly determine the long term variation in the trapped flux magnitudes and location. The same study, however, demonstrated that this relationship breaks down on shorter time periods. This is clearest for events where the plasmapause moves inwards, allowing chorus to accelerate electrons to higher energies at comparatively low L-shells, and then outwards, "stranding" this high energy population inside the plasmapause. A particularly dramatic example of this is the recent reports of the "third radiation belt" observed by the Van Allen probes [Baker et al., 2013], and subsequently successfully modeled [e.g. Thorne et al., 2013]. One should note this sort of dynamical behavior is not uncommon, and can also lead to electron flux enhancements inside the plasmapause at non-relativistic energies [Lichtenberger et al., 2013]. There have also been previous studies reporting links between the plasmapause location and relativistic electron precipitation caused by chorus [e.g. Johnston and Anderson, 2010] and EMIC waves [Carson, Rodger and Clilverd, 2013].

The POES (Polar Orbiting Environmental Satellite) network of polar orbiting satellites (formerly known as TIROS - Television and InfraRed Observation Satellite) are operated by NOAA (National Oceanic and Atmospheric 
Administration). These satellites have been running from NOAA-05 in 1978 up to the present in Sun-synchronous orbits at varying Equatorial Crossing Times (ECT). EUMETSAT added the MetOp-02 satellite to the POES network with the same particle instrumentation in May 2007. The MEPED (Medium Energy Proton and Electron Detector) instrument is the focus of our study and the data have been widely used in previous research on electron precipitation [e.g Callis, 1997; Millan et al., 2010; Carson, Rodger and Clilverd, 2013]. The MEPED instrument is an electron flux detector, which takes measurements at both $0^{\circ}$ and $90^{\circ}$ pitch angles for 3 integral energy ranges. A full description of the instrument is included in Section 2.1. The main advantage of using this instrument for magnetospheric research comes from it's long data duration, which spans more than two solar cycles with almost continuous data coverage.

The goal of our study is undertake a superposed epoch analysis of precipitating electron flux so that we can perform fitting techniques to provide an accurate empirical EEP model. This model can then be used to give an approximate precipitating electron flux inside and outside of the plasmapause due to chorus and plasmaspheric hiss.

\section{Data acquisition}

To get an average of the electron fluxes around the plasmapause at different geomagnetic conditions we use data collected from the long running POES satellite constellation.

\subsection{POES electron flux instrument}

The NOAA/POES MEPED sensor provides two kinds of particle count rate measurements including two directional measurements of protons ( 0.03 to $>6.9 \mathrm{MeV}$, with 6 energy steps labeled $\mathrm{P} 1$ to $\mathrm{P} 6)$ and electrons $(0.03-2.5 \mathrm{MeV}$, in 3 energy ranges, labeled E1 (>30 keV), E2 (>100 keV) and E3 $(>300 \mathrm{keV}))$. There are two telescopes sampling both protons and electrons pointing in different directions, each with a viewing width of $\pm 15^{\circ}$. The $0^{\circ}$ detector is directed along the Earth-spacecraft radial direction, and the axis of the $90^{\circ}$ detector is perpendicular to this (anti-parallel to the spacecraft velocity vector). Modeling work has established that the $0^{\circ}$ telescope monitors particles in the atmospheric bounce loss cone that will enter the Earth's atmosphere below the satellite when the spacecraft is poleward of $\mathrm{L} \approx 1.5$ 1.6, while the $90^{\circ}$ telescope monitors trapped fluxes or those in the drift loss cone, depending primarily upon the $L$ shell [Rodger et al., 2010b, Appendix A].

The MEPED instrument has been updated as part of the SEM-2 subsystem and these changes have been implemented from NOAA-15 to NOAA-19 and the MetOp-2 satellite. For our study we consider only observations made using SEM-2, and hence only the satellites listed above are considered. We use the equations given in Lam et al. [2010] to convert from instrument counts to integral electron flux values with units of $\mathrm{e}^{-} \mathrm{cm}^{-2} \mathrm{sr}^{-1} \mathrm{~s}^{-1}$. The Lam et al. [2010] equations also remove proton contamination for periods observed outside of the South Atlantic Magnetic Anomaly (SAMA) and solar proton events. A full description of the SEM-2 system which includes the MEPED instrument can be found in Evans and Greer [2004].

\subsection{MLT and L shell data binning}

The aim of this paper is to characterize energetic electron fluxes both inside and outside of the plasmapause and to do this we sort our data by Magnetic Local Time (MLT).
Figure 1 is taken from Summers, Ni and Meredith [Figure 21,2007 ], showing a schematic of the plasmapause location including a drainage plume. The main areas of chorus wave and plasmaspheric hiss activity are also shown, separated by the plasmapause. In this study we have selected two MLT sectors to determine the effects of each wave type, and to characterize the resultant electron precipitation occurring inside and outside of the plasmapause. We identify the regions which are chorus-dominated as spanning 01:00-08:00 MLT (morning) and hiss-dominated as spanning 11:00-16:00 MLT (afternoon). These two regions are shaded in Figure 1 with the grey region showing the morning sector (chorus wave dominated) and the purple region shows the afternoon sector (plasmaspheric hiss dominated).

The precipitating electron fluxes measured by the POES $0^{\circ}$ pointing telescope between 1999 and 2012 are binned by both IGRF L shell and time with respective resolutions of 0.2 $\mathrm{L}$ and 20 minutes for each MLT sector and integral energy range. Observations from inside and around the SAMA are excluded before the measurements are combined. There are 42 bins in $\mathrm{L}$-shell ranging from $\mathrm{L}=1.8$ to $\mathrm{L}=10.2$, when discussed in this study each bin will be referred to by its central L-shell value (e.g. the first bin is at $\mathrm{L}=$ 1.9). It should be noted that the lowest L-shell considered, $\mathrm{L}=1.8$, is above the minimum $\mathrm{L}$-shell required to ensure that the $0^{\circ}$ MEPED instrument is observing precipitating electrons (Section 2.1). To maximize the quality and MLT range of the electron flux data, results from all available POES satellites are combined and the median taken from the available fluxes in each bin.

\section{Determination of storm epochs}

To create an average dataset of how electron precipitation varies in different geomagnetic conditions (i.e. during a geomagnetic storm and the gradual return to background activity) we undertake a superposed epoch analysis for each MEPED energy channel and MLT sector around a defined geomagnetic storm. To begin our investigation we create a superposed epoch dataset ranging from 5 days before to 15 days after a geomagnetic storm allowing both quiet (pre and post storm) and active (storm time) geomagnetic activity to be compared.

While Kp is commonly used in energetic electron studies [e.g., Meredith et al., 2006; Whittaker et al., 2013], Dst is chosen as the geomagnetic index for this study as it is continuous, rather than Kp which has specific discrete values (e.g. 0, 0.3, 0.7, etc). Dst is a measure of the energy density of the ring current measured at several equatorial stations around the globe by determining differences in the horizontal component of the Earth's magnetic field [Sugiura, 1964]. These values are generally negative and we take a value of Dst $\leq-50 \mathrm{nT}$ as describing geomagnetic stormtime [Borovsky and Denton, 2006]. To reduce the possibility of a storm being counted as an epoch several times, an extra condition is applied to the Dst detection algorithm which states that the neighboring Dst values ( \pm 1 hour) must have a higher value (i.e., the Dst value chosen is a local minimum).

The total number of Dst storm epochs identified during the 13 year time period was 1144. The POES/MEPED proton data was then checked during each storm event in order to remove any epochs which include Solar Proton Events (SPE). The POES/MEPED electron telescopes are sensitive to proton contamination [Yando et al., 2011] and while a previous study [Whittaker et al., 2014] has shown that the Lam et al. [2010] proton removal equations give a good approximation of the true electron flux, the approach fails during solar proton events and inside the SAMA. Hence, 
we remove any epochs which MEPED reports as having a differential proton flux $>10 \mathrm{p}^{+} \mathrm{cm}^{-2} \mathrm{sr}^{-1} \mathrm{~s}^{-1} \mathrm{keV}^{-1}$ in the $\mathrm{P} 5$ channel (at an energy of $2.63 \mathrm{MeV}$ ) during any time in the epoch. This SPE detection process removed 356 epochs. The remaining 788 epochs were then combined by taking the median of each L shell bin over a 12 hour period within the -5 to +15 day range around the geomagnetic storm. This results in 41 epoch-time values with $42 \mathrm{~L}$ shell ranges for each integral electron energy range.

The left panel of Figure 2 shows the median Dst value taken from these 788 epochs at 12 hour intervals. There is a smooth variation in the Dst values which take approximately 7 days to return to quiet activity $(-14 \mathrm{nT})$ after the storm peaks at zero epoch (median of $-66 \mathrm{nT}$ ). The right panel of Figure 2 shows the calculated plasmapause location $\left(\mathrm{L}_{p p}\right)$ for this epoch based on non-MLT dependent model equations in O'Brien and Moldwin [2003]. The model given in this paper has an associated error of $\pm 1 \mathrm{~L}$ shell and we select an $\mathrm{L}_{p p}$ value that is consistently $0.5 \mathrm{~L}$ lower than the equations in O'Brien and Moldwin [2003]. We will later show this $\mathrm{L}_{p p}$ is highly consistent with the precipitating electron fluxes. The error range is shown in Figure 2 as the dashed black lines and our chosen plasmapause location with the $0.5 \mathrm{~L}$ shift is shown as the solid black line with + signs indicating the position at each 12 hour interval.

\section{EEP characteristics outside of the plasmapause}

To determine electron precipitation occurring outside the plasmapause we investigate the chorus dominated morning MLT sector of Figure 1 (01:00 - 08:00). Figure 3 shows the variation in EEP fluxes around the storm epoch for all three channels of the MEPED instrument in the morning MLT sector, $>30 \mathrm{keV}$ (top left panel), $>100 \mathrm{keV}$ (top right panel) and $>300 \mathrm{keV}$ (lower left panel). A power law fit, previously shown to be the best type of electron spectral fit to apply [Whittaker et al., 2013], is applied to each L shell and time bin across the three energies. The spectral index of this fit is shown in the lower right panel of Figure 3.

The fitting of the flux in the three integral electron channels is performed by applying a linear fit to the $\log _{10}$ of the energy and flux values (Equation (1)), giving a power law fit on linear axes (Equation (2)) as shown below.

$$
\begin{aligned}
\log _{10} j & =\gamma \log _{10} E+\log _{10} \alpha \\
j & =\alpha E^{\gamma}
\end{aligned}
$$

Where:

$$
j=\text { integral flux at energy } \mathrm{E}\left(\mathrm{e}^{-} \mathrm{cm}^{-2} \mathrm{sr}^{-1} \mathrm{~s}^{-1}\right)
$$

The previously described plasmapause location fits extremely well to the data of all three energies, describing the boundary between high and low precipitating fluxes. To provide information on precipitating fluxes outside the plasmapause we provide two simulations; $>30 \mathrm{keV}$ and the power law fit spectral index. The ability to reproduce both of these epoch types will allow precipitating electron fluxes of any energy to be calculated relative to the plasmapause location as a storm progresses.

\section{1. $>30 \mathrm{keV}$ simulation process}

We begin by investigating the $>30 \mathrm{keV}$ epoch (top left panel of Figure 3). The data shows that the highest precipitating fluxes are in the 12 hour bin around storm time, meaning that no delay between Dst and flux needs to be incorporated. This matching of electron flux to the Dst minimum indicates that the precipitation due to chorus wave interaction occurs within 6 hours of the main phase of the storm.

We produced time varying plots of the superposed epoch analyzed precipitating flux at 21 different distances from the plasmapause, ranging from $1.5 \mathrm{~L}$ inside the plasmapause in $0.25 \mathrm{~L}$ shell increments up to $3.5 \mathrm{~L}$ outside the plasmapause. A selection of these are shown by the blue solid lines in Figure 4. The black dashed lines in this figure show the average precipitating flux before the storm at each distance and it can be seen that the fluxes take approximately 7 days to recover, on a similar timescale to Dst.

For each distance from the plasmapause we plotted the absolute Dst values against the flux and applied a power law fit in the form of Flux $=a_{1}|D s t|^{a_{2}}+a_{3}$. These fits were performed on the 41 time points at each distance and produced adjusted $\mathrm{r}^{2}\left(\mathrm{r}_{a d j}^{2}\right)$ values of greater than 0.95 at all distances outside the plasmapause and an average $\mathrm{r}_{a d j}^{2}$ of 0.8 inside the plasmapause. When the coefficients of each fit were compared, the $a_{2}$ coefficient was close to being constant with an average value of 2.8. The fits to the flux and Dst were then reapplied with this constant $a_{2}$ value, the $a_{1}$ and $a_{3}$ values could then be described by double Gaussians as a function of distance from the plasmapause. This final equation is shown in Equation (3) providing flux with units of $\mathrm{e}^{-} \mathrm{cm}^{-2} \mathrm{sr}^{-1} \mathrm{~s}^{-1}$.

$$
\text { Flux }_{\text {chorus }}=a\left(S_{p p}\right)|D s t|^{2.8}+b\left(S_{p p}\right)
$$

where:

$$
\begin{aligned}
a\left(S_{p p}\right) & =0.7 e^{-\left(\frac{S_{p p}-1}{0.96}\right)^{2}}+0.21 e^{-\left(\frac{S_{p p}-2.3}{1.43}\right)^{2}} \\
b\left(S_{p p}\right) & =904 e^{-\left(\frac{S_{p p}-1.77}{1.27}\right)^{2}}+9.65 \times 10^{16} e^{-\left(\frac{S_{p p}-431}{75}\right)^{2}} \\
S_{p p} & =\text { distance from the plasmapause (in L) }
\end{aligned}
$$

These equations were then tested at different distances from the plasmapause, these are shown as the red dashed lines on the example plots shown in Figure 4. These model fluxes match very well to the lines representing observed flux outside the plasmapause but fit less well inside the plasmapause. As the electron precipitation from inside the plasmapause in this MLT sector is low, we conclude this equation performs adequately in modeling the fluxes outside the plasmapause.

\subsection{Flux spectral index simulation}

We now investigate the electron flux spectral index $(\gamma)$ for the varying geomagnetic conditions shown in the lower right panel of Figure 3. This is performed in a similar way to the $>30 \mathrm{keV}$ flux simulation in Section 4.1.

The spectral index is determined at the same 21 distances from the plasmapause as the $>30 \mathrm{keV}$ fluxes were. A selection of these are shown as the blue solid lines in Figure 5. The fit spectral index is negative as we are fitting integral energy ranges (i.e. $>100 \mathrm{keV}$ channel has to have lower fluxes than the $>30 \mathrm{keV}$ channel). The minimum in spectral index again appears to occur in the 12 hours around the Dst minimum with a similar 7 day recovery time. We take each of the spectral index lines at different distances from the plasmapause and plot them against Dst. It should be noted that as both the Dst and the gradient are negative there is no need to take the absolute Dst value in this case. The spectral index to Dst relations correlate well with a 
linear fit $\left(a_{2}=1\right)$, the amplitude $\left(a_{1}\right)$ and constant $\left(a_{3}\right)$ of the fit can once again be characterized by their distance from the plasmapause. This equation is shown in Equation 4.

$$
\gamma_{\text {chorus }}=c\left(S_{p p}\right) D s t-d\left(S_{p p}\right)
$$

where:

$$
\begin{aligned}
c\left(S_{p p}\right) & =0.02 e^{-\left(\frac{S_{p p}-0.44}{1.53}\right)^{2}}+0.03 e^{-\left(\frac{S_{p p}-2.82}{2.5}\right)^{2}} \\
d\left(S_{p p}\right) & =0.86 e^{-\left(\frac{S_{p p}-1.05}{1.51}\right)^{2}}+0.47 e^{-\left(\frac{S_{p p}-3.25}{1.395}\right)^{2}} \\
S_{p p} & =\text { distance from the plasmapause (in L) }
\end{aligned}
$$

The coefficients of the fit $\left(c\left(S_{p p}\right)\right.$ and $\left.d\left(S_{p p}\right)\right)$ are easily characterized by a double Gaussian, with the 21 points producing an $r_{a d j}^{2}=0.994$ for the equation of $c\left(S_{p p}\right)$ and $r_{a d j}^{2}=0.91$ for the $d\left(S_{p p}\right)$ fit. After testing Equation 4, the reproduction of the spectral indicies inside the plasmapause appear to not fit well so an extra condition is applied to $d\left(S_{p p}\right)$ :

$$
\begin{aligned}
& \text { Spp } \geq 0 \\
& \quad d\left(S_{p p}\right)=0.86 e^{-\left(\frac{S_{p p}-1.05}{1.51}\right)^{2}}+0.47 e^{-\left(\frac{S_{p p}-3.25}{1.395}\right)^{2}} \\
& \quad \quad \operatorname{Spp}<0 \\
& \quad d\left(S_{p p}\right)=0.3
\end{aligned}
$$

This extra condition for $d\left(S_{p p}\right)$ greatly improves the model and the spectral indicies calculated from Equation 4 are shown as the red dashed lines in Figure 5 as a comparison.

\subsection{Model confidence}

Examination of Figures 4 and 5 shows very clearly that the equations do an excellent job of reproducing the fluxes and spectral index outside the plasmapause. Taking $1.5 \mathrm{~L}$ outside the plasmapause as an example, the average $>30$ $\mathrm{keV}$ flux difference between the model and observations is $1476 \mathrm{e}^{-} \mathrm{cm}^{-2} \mathrm{sr}^{-1} \mathrm{~s}^{-1}$ with an interquartile range of 457 , giving a range of between $10^{3}$ and $2 \times 10^{3}$ (this average value is $1 \%$ of the storm time flux and $30 \%$ of the quiet time flux). This range is well below the average flux variation during quiet geomagnetic conditions (shown by the dashed black line), indicating the model error is small. Performing a similar analysis for the spectral index gives a mean difference of 0.06 with an interquartile range of 0.05 , resulting in a range between 0.01 and 0.11 , which is again very small compared to the data values.

As a more complete test of these equations, the $>30 \mathrm{keV}$ and spectral index epoch panels from Figure 3 are recreated using Equations (3) and (4). These are shown in Figure 6 with the $>30 \mathrm{keV}$ flux variation shown in the top panels, and the spectral index variation shown in the lower panels. When we consider the $>30 \mathrm{keV}$ flux epoch, the simulation (top right panel) looks very similar to the data (top left panel). The biggest source of error exists on the storm day inside the plasmapause, where the simulation reports a sevenfold increase in flux in this area. If we only consider the simulation outside the plasmapause then the range of $>30 \mathrm{keV}$ flux differences is between a factor of 0.6 to 1.6 of the data with a mean value of 1.06 and a standard deviation of 0.27 . This indicates that the error in this model is approximately $30 \%$, although it should be noted that the biggest differences are mostly in the very low flux areas. When we apply the same analysis of Figure 6 to the spectral index simulation (lower right panel) and data (lower left panel) we again see strong similarities between the two. The largest difference between data and simulation is again just inside the plasmapause at the peak of the storm, with the simulation giving a spectral index 4 times lower than the data. The spectral index values outside the plasmapause show that the simulation underestimates the observations, with an average ratio of 0.93 and standard deviation of 0.07 giving an average error of approximately $15 \%$. The areas where the error is greatest are at high $\mathrm{L}$ shells $(\mathrm{L}=7.5)$ around storm time, with minimum and maximum ratios (simulation to observations) of 0.31 and 1.2 respectively.

The simulations in Figure 6 also show that at the highest L shells, the simulations do not seem to represent the epoch very well for $\mathrm{L} \geq 8.5$. We therefore advise that the model equations are not used beyond $\mathrm{L}=8.5$. This is indicated on Figure 6 by the solid black line which corresponds to approximately $3 \mathrm{~L}$ outside the geomagnetically quiet plasmapause.

\section{EEP characteristics inside the plasmapause}

To determine electron precipitation occurring inside the plasmapause we investigate the plasmaspheric hiss dominated MLT sector (11:00 - 16:00). Figure 7 shows the electron precipitation variation after a superposed epoch analysis for all three channels of the MEPED instrument, $>30 \mathrm{keV}$ (top left panel), >100 keV (top right panel) and $>300 \mathrm{keV}$ (lower left panel) in a similar manner to Figure 3 and using the same color scales. In comparison to Figure 3 the fluxes outside the plasmapause in the afternoon MLT sector are lower in magnitude. This seems reasonable as our chosen MLT sector corresponds to the smaller area of chorus wave activity, as shown in Figure 1. The $>300 \mathrm{keV}$ electron fluxes inside the plasmapause are higher than observed in the morning MLT sector, this indicates that our chosen MLT sectors are behaving as expected.

\subsection{Energetic distribution of hiss induced precipitation}

In Figure 3 the energy spectra of the chorus induced electron precipitation is easily observed. However, this is more difficult inside the plasmapause for the afternoon MLT sector. Examination of Figure 7 shows that the peak flux in the $>300 \mathrm{keV}$ channel occurs in the bin 48 hours ( \pm 6 hours) after the main phase of the storm at $\mathrm{L}=$ 4.1. This flux enhancement is very difficult to see in the other integral energy channels even with a narrow color table range indicating there is a lack of any obvious flux enhancement inside the plasmapause in the $>30 \mathrm{keV}$ and $>100 \mathrm{keV}$ energy channels at this specific time. The $>100$ $\mathrm{keV}$ channel shows some small precipitation enhancement approximately 36 hours from the main phase of the storm on an $\mathrm{L}$ shell range of 3.9 to 4.3 and there is no visible effect in the $>30 \mathrm{keV}$ channel. This correlates well with the results from Summers, et al. [2008] stating that electron loss due to pitch angle scattering is both L shell and energy dependent. The typical precipitation time given by these authors states that for 100 to $200 \mathrm{keV}$ electrons electrons are lost in approximately one day. For the $>30 \mathrm{keV}$ channel this suggests the losses happen much faster and are probably hidden in our observations by the 12 hour time resolution, with the main hiss induced loss happening at the epoch time and visually lost amongst the chorus induced precipitation.

As a further test of these results we investigate the P6 proton channel on the MEPED instrument. The geometric factor related to this high energy proton telescope $(>6.9 \mathrm{MeV}$ protons) indicates that it functions very well as a relativistic electron detector [Yando et al., 2011]. It should be noted that there will be little to no actual relativistic protons to contaminate the results as we have removed epochs showing high energy protons as part of our SPE removal. The 
superposed epoch analysis of this telescope in the afternoon MLT sector is shown in the lower right panel of Figure 7 with the same $\log _{10}$ color scale as the $>300 \mathrm{keV}$ channel. The main precipitating flux can be seen at approximately 96 hours from the main phase of the storm with a narrower $\mathrm{L}$ shell profile. The energy of this channel has been determined in previous studies as $>800 \mathrm{keV}$ [e.g. Carson, Rodger and Clilverd, 2013; Rodger et al., 2010b], as this is when the geometric factor for the electrons in this channel is greater than $10^{-3} \mathrm{~cm}^{2}$ sr. We can also make an estimate of the upper energy limit, from the geometric factors given in Yando et al. [2011], the P6 channel would respond more strongly than the $>300 \mathrm{keV}$ for electrons above $1.4 \mathrm{MeV}$. Thus, as the fluxes in the P6 channel are lower than the $>300 \mathrm{keV}$ channel from Figure 7, we can assume the energy of a high proportion of precipitating electrons in the P6 channel are between 0.8 and $1.4 \mathrm{MeV}$.

An interesting point of note is that there is no evidence of chorus induced precipitation in the P6 observations. The morning MLT superposed epoch analysis was also investigated and showed the same lack of precipitating flux outside the plasmapause. This suggests that relativistic electrons are not strongly affected by chorus wave interaction.

\subsection{Hiss induced EEP simulation $(>300 \mathrm{keV})$}

We now proceed to simulate the fluxes inside the plasmapause. From our observations we can only simulate the $>300$ and $>800 \mathrm{keV}$ (P6) channels and we begin with the $>300 \mathrm{keV}$ observations.

We initially attempted the same method of simulation as performed in Sections 4.1 and 4.2, however, taking flux data at different distances from the plasmapause returned no correlation with the Dst values. We therefore took a different approach and investigated flux at specific L shell values for the $>300 \mathrm{keV}$ channel. A selection of these can be seen in panels a) to d) of Figure 8. The solid blue line of these panels shows the flux from the $>300 \mathrm{keV}$ channel in the lower left panel of Figure 7 at $\mathrm{L}=3.3$ (panel a), $\mathrm{L}=$ 3.7 (panel b), $\mathrm{L}=4.1$ (panel c) and $\mathrm{L}=4.5$ (panel d).

Panels a) and b) of Figure 8 , at $\mathrm{L}=3.3$ and $\mathrm{L}=3.7$ respectively, show a single peak in the flux variations centered on the second day from the main phase of the storm. Panels c) and d), showing flux at $\mathrm{L}=4.1$ and 4.5, have two peaks at 0 and 2 days from the main phase of the storm. This 0 day peak is from flux values outside the plasmapause and is removed before the analysis begins at all $\mathrm{L}$ shells. The flux at each $0.2 \mathrm{~L}$ row from $\mathrm{L}=3.3$ to $\mathrm{L}=$ 4.5 is compared to the Dst value from 48 hours previously. These comparisons once again show a relation of the form Flux $=a_{4}\left|D s t_{-48}\right|^{a_{5}}$ with a constant $a_{5}$ of 0.065 . The amplitude $\left(a_{4}\right)$ was fitted with a single Gaussian using the L shell value as the variable. A double Gaussian was not used due to the lower number of data points for this analysis.

$$
\text { Fluxhiss }>300=\mathrm{e}(\mathrm{L}) \mid \text { Dst }\left._{-48}\right|^{0.065}
$$

where:

$$
\begin{aligned}
e(L) & =119 e^{-\left(\frac{L-4.1}{3}\right)^{2}} \\
L & =\mathrm{L} \text { shell value }
\end{aligned}
$$

Equation (5) shows the hiss simulation equation in the $>300$ $\mathrm{keV}$ electron flux channel. A test of this equation has been added to panels a) to d) of Figure 8 as the red dashed lines. This simulation follows the data well with a standard deviation of $1.25 \mathrm{e}^{-} \mathrm{cm}^{-2} \mathrm{sr}^{-1} \mathrm{~s}^{-1}$. The maximum difference between the simulation and the data is $5.75 \mathrm{e}^{-} \mathrm{cm}^{-2} \mathrm{sr}^{-1} \mathrm{~s}^{-1}$ (4\% of the observed flux) at $\mathrm{L}=4.5$ and 12 hours from the main phase of the storm.

Panel e) of Figure 8 shows the $>300 \mathrm{keV}$ epoch from Figure 7 on a linear color scale, with the plasmapause shown as the black dashed line. We then use Equation (5) to attempt to replicate panel e). The simulation is shown in panel $\mathrm{f}$ ) with the same color scale. Using the 48 hour delayed Dst values gives a simulation which appears to agree well by eye. The standard deviation of the difference between the simulation and observations is less than $1 \%$ of the peak flux and approximates to $8 \%$ of the enhancement from background $\left(135 \mathrm{e}^{-} \mathrm{cm}^{-2} \mathrm{sr}^{-1} \mathrm{~s}^{-1}\right)$ to peak $\left(153 \mathrm{e}^{-} \mathrm{cm}^{-2} \mathrm{sr}^{-1} \mathrm{~s}^{-1}\right)$ precipitating electron flux inside the plasmapause.

\subsection{Hiss induced EEP simulation (relativistic electrons)}

As we have simulated the $>300 \mathrm{keV}$ channel we now move onto a simulation of the $>800 \mathrm{keV}$ channel. The superposed epoch of the $>800 \mathrm{keV}$ channel in Figure 7 (lower right panel) looks very similar to the $>300 \mathrm{keV}$ superposed epoch (lower left panel). The main differences being the L shell range of precipitating electrons and the time lag with respect to Dst. We therefore apply the same simulation technique as used for the $>300 \mathrm{keV}$ electron channel (Section 5.2).

The superposed epoch of the $>800 \mathrm{keV}$ precipitating electrons is reproduced in panel $(\mathrm{g})$ of Figure 8 on a linear color scale. The flux at each $0.2 \mathrm{~L}$ shell between $\mathrm{L}=3.3$ and $\mathrm{L}=4.5$ is taken and compared to the Dst value from 96 hours previously. The fitting equation is in the same format as Equation (5), with the same $a_{5}$ value of 0.065 used. The $a_{4}$ value is then calculated with a fitted Gaussian and the coefficients are given below.

$$
\text { Flux }_{\text {hiss }>800}=\mathrm{f}(\mathrm{L}) \mid \text { Dst }\left._{-96}\right|^{0.065}
$$

where:

$$
\begin{aligned}
f(L) & =111 e^{-\left(\frac{L-4}{2.3}\right)^{2}} \\
L & =\mathrm{L} \text { shell value }
\end{aligned}
$$

The simulation of this superposed epoch is shown in panel $\mathrm{h}$ ) of Figure 8 and on the same color scale as the observations in panel $\mathrm{g}$ ). When we compare the differences between the observations and the simulation we find that the average difference (using absolute values) is $2.29 \mathrm{e}^{-} \mathrm{cm}^{-2} \mathrm{sr}^{-1} \mathrm{~s}^{-1}$ and a standard deviation of $2.417 \mathrm{e}^{-} \mathrm{cm}^{-2} \mathrm{sr}^{-1} \mathrm{~s}^{-1}$. The median difference corresponds to $\sim 2 \%$ of the peak observed flux and $13 \%$ of the enhancement from background (125 $\left.\mathrm{e}^{-} \mathrm{cm}^{-2} \mathrm{sr}^{-1} \mathrm{~s}^{-1}\right)$ to peak $\left(143 \mathrm{e}^{-} \mathrm{cm}^{-2} \mathrm{sr}^{-1} \mathrm{~s}^{-1}\right)$ observed flux.

\section{Discussion}

We now have a complete model description of the fluxes outside and inside the plasmapause due to chorus and plasmaspheric hiss. As a confirmation of our results we investigate the DEMETER (Detection of Electro-Magnetic Emissions Transmitted from Earthquake Regions) ICE (Instrument Champ Electrique) instrument observations to determine the wave activity in the chorus band during our superposed epoch analysis. The ICE instrument performs a continuous survey of a wide range of DC and AC electric fields with a high sensitivity and a 1 second temporal resolution. A full description of the instrument can be 
found in Berthelier et al. [2006]. A previous study [Hayosh et al., 2013] has linked electron precipitation to chorus wave activity using ICE and POES data in two case studies. Panel a) of Figure 9 shows a superposed epoch analysis using the same epochs as we used for the POES analysis, but limited to those which occurred in the DEMETER satellite lifetime of 2006-2011. The model plasmapause, as calculated in Section 3, is included as the dashed line on this plot. The color scale indicates the variation in the power of lower band chorus waves. This plot shows that the chorus wave activity peaks at storm time and is largely contained outside of the plasmapause. This confirms that strong chorus wave activity is present during the main period when the electron precipitation is enhanced. Note also that there is enhanced wave power inside the plasmapause for some days after the storm time zero epoch. This is likely to be caused by plasmaspheric hiss, which can overlap the frequency band of lower-band chorus in that L-shell range.

To visually show the difference in electron flux enhancement effects between chorus and hiss we plot both observations together with the Dst value. Panel b) of Figure 9 shows the peak electron flux for each wave type $(>30 \mathrm{keV}$ for chorus and $>300 \mathrm{keV}$ for hiss). The chorus precipitating flux is shown as the black dashed line with + symbols, this occurs at $\mathrm{L}=5.3$ and has a peak electron flux of $1.4 \times 10^{5}$ $\mathrm{e}^{-} \mathrm{cm}^{-2} \mathrm{sr}^{-1} \mathrm{~s}^{-1}$. The peak hiss precipitating flux occurs at $\mathrm{L}=4.1$ and is shown by the green dashed line with diamond markers, the maximum flux at this $\mathrm{L}$ shell is 153.7 $\mathrm{e}^{-} \mathrm{cm}^{-2} \mathrm{sr}^{-1} \mathrm{~s}^{-1}$. The Dst value is also shown as the blue solid line for comparison. The difference in precipitating electron enhancements is very clear in this figure with the chorus having an effect over three orders of magnitude larger than hiss. This is an expected result as the average population of $>30 \mathrm{keV}$ electrons is much larger than the average population of $>300 \mathrm{keV}$ electrons. A comparison of the strength of the effects of chorus and hiss can be found by comparing the peak $>300 \mathrm{keV}$ flux inside and outside of the plasmapause. The peak flux above the plasmapause for the $>300 \mathrm{keV}$ precipitating electrons is $212.7 \mathrm{e}^{-} \mathrm{cm}^{-2} \mathrm{sr}^{-1} \mathrm{~s}^{-1}$ and the peak inside the plasmapause is $153 \mathrm{e}^{-} \mathrm{cm}^{-2} \mathrm{sr}^{-1} \mathrm{~s}^{-1}$. When we consider these fluxes as enhancements from the background flux value we find that the chorus induced enhancement has an effect approximately 4.5 times stronger than the hiss induced enhancement. Panel c) of Figure 9 shows just the hiss peak flux on a much reduced y-axis range. The 2 day delay effect can be clearly seen as well as the small chorus effect at the time of the storm.

Our epochs have been created using a median Dst value in the statistical model we have created, this means that our equations have not included any positive Dst values. When used for comparison in case studies this is important as the effects of Dst $>0$ on the model are unknown. This is especially true in the case of the $>30 \mathrm{keV}$ flux which uses the absolute value of Dst and hence a positive Dst would increase the model precipitation level.

\section{Conclusions}

We have performed a superposed epoch analysis of precipitating electron flux taken from the POES/MEPED instrument. The epoch has been based on the minimum value of Dst during a geomagnetic storm, taken when Dst drops below $-50 \mathrm{nT}$. Our results have been split into two MLT regions to focus upon the different enhancement effects of chorus and plasmaspheric hiss waves on the electron precipitation. From our superposed epoch analysis we have shown that for the morning MLT sector, the precipitating electron flux outside the plasmapause is greatly enhanced at storm time with this flux correlating strongly with the Dst value and distance from the modeled plasmapause location. In contrast the afternoon MLT sector shows time varying precipitating electron flux inside the plasmapause dependent upon electron energy. The $>300 \mathrm{keV}$ channel precipitation peak occurs with a 2 day lag from the Dst values and the relativistic electron precipitation peak occurs 96 hours from the main phase of the storm. Neither precipitation profile is dependent upon the plasmapause position.

By taking electron flux values at constant distances from the modeled plasmapause, we have produced a model description of the enhancements in flux for the morning MLT sector associated with chorus waves. The $>30 \mathrm{keV}$ electron flux model is given in Equation 3, along with the modeled power law fit spectral index response in Equation 4. The combination of these two equations allows us to model the full precipitating electron energy response during a geomagnetic storm outside the plasmapause. The associated error in this model has shown to be $\sim 30 \%$ for the $>30$ $\mathrm{keV}$ flux values and $\sim 15 \%$ for the spectral index. We have also observed that relativistic electrons are very unlikely to precipitate outside the plasmapause.

The electron flux enhancements inside the plasmapause in the afternoon MLT sector, associated with plasmaspheric hiss, have been modeled for electrons with energies above $300 \mathrm{keV}$. The $>300 \mathrm{keV}$ model, shown in Equation 5, depends on the $\mathrm{L}$ shell and operates on a 2 day lag from the Dst value. The average error in the enhancement of this model from the data is $8 \%$. The simulation of the P6 channel (Equation (6)) also depends on L shell and relies on a 4 day lag from the Dst value consistent with the results of Summers, et al. [2008]. The average error in the precipitating flux enhancement of this model is $13 \%$. There are no observations of the precipitating flux inside the plasmapause for the lower energies as these will be combined with the chorus precipitation within 12 hours of the main phase of the storm.

The models we have produced can be used to estimate precipitating electron fluxes based on real time Dst and plasmapause location data. The European Union FP7 funded project, PLASMON, intends to assimilate near real time measurements of plasmaspheric densities into a dynamic plasmasphere model using whistler waves detected by a VLF ground network (e.g. http://plasmon.elte.hu/, Collier et al. [2011], Lichtenberger et al. [2013]). This project complements our EEP precipitation model equations providing values which can be compared both to satellite measurements (POES, DEMETER and the more recent Radiation Belt Storm Probes missions) and ground based VLF perturbations (e.g. AARDDVARK network, http://www.physics.otago.ac.nz/space/AARDDVARK_homepage.htm). The combination of the data results from PLASMON and our model will allow a near real-time estimate to be made of precipitating energetic electron fluxes.

Acknowledgments. The research leading to these results has received funding from the European Community's Seventh Framework Programme ([FP7/2007-2013]) under grant agreement number 263218. The authors wish to thank the NOAA personnel who developed, maintain, and operate the NOAA/POES spacecraft. The data used in this paper are available at NOAA's National Geophysical Data Center (NGDC - NOAA 15-19 and MetOp-02 MEPED data).

\section{References}

Andersson, M., P. T. Verronen, S. Wang, C. J. Rodger, M. A. Clilverd, and B. R. Carson (2012), Precipitating radiation belt electrons and enhancements of mesospheric hydroxyl during 20042009., J. Geophys. Res., 117(D09304), doi:10.1029/2011JD017246. 
Andersson, M., P. T. Verronen, C. J. Rodger, M. A. Clilverd, and S. Wang (2014), Longitudinal hot-spots in the mesospheric $\mathrm{OH}$ variations due to energetic electron precipitation, Atmos. Chem. Phys., 4, doi:10.5194/acp-14-1095-2014.

Baker D. N., S. G. Kanekal, V. C. Hoxie, M. G. Henderson, X. Li, H. E. Spence, S. R. Elkington, R. H. W. Friedel, J. Goldstein, M. K. Hudson, G. D. Reeves, R. M. Thorne, C. A. Kletzing, S. G. Claudepierre (2013), A Long-Lived Relativistic Electron Storage Ring Embedded in Earths Outer Van Allen Belt, Science, 340(6129), doi:10.1016/science.1233518.

Berthelier, J. J., M. Godefroy, F. Leblanc, M. Malingre, M. Menvielle, D. Lagoutte, J.Y. Brochot, F. Colin, F. Elie, C. Legendre, P. Zamora, D. Benoist, Y. Chapuis, J. Artru, and R. Pfaff (2006), ICE, the electric field experiment on DEMETER, PSS, 54(5), doi:10.1016/j.pss.2005.10.016.

Borovsky, J. E., and M. H. Denton (2006), Differences between CME driven storms and CIR driven storms, J. Geophys. Res., 111, A07S08, doi:10.1029/2005JA011447.

Brasseur, G., and S. Solomon (2005), Aeronomy of the Middle Atmosphere, third ed., D. Reidel Publishing Company, Dordrecht.

Callis, L. B. (1997), Odd nitrogen formed by energetic electron precipitation as calculated from TIROS data, Geophys. Res. Lett., 24 (24), doi:10.1029/97GL03276

Carson, B., C. J. Rodger and M. A. Clilverd (2013), POES satellite observations of EMIC-wave driven relativistic electron precipitation during 1998-2010, J. Geophys. Res., 118, doi:10.1029/2012JA017998.

Collier, A. B., J. Lichtenberger, M. Clilverd, B. Heilig, M. Vellante, J. Manninen, C. J. Rodger, A. Jorgensen, J. Reda, R. Holzworth, R. Friedel, (2011), PLASMON: Data assimilation of the Earth's plasmasphere, General Assembly and Scientific Symposium, 2011 XXXth URSI, 13-20 Aug. 2011, doi:10.1109/URSIGASS.2011.6051134.

Evans, D. S., and M. S. Greer (2004), Polar orbit environmental space satellite space environment monitor 2: Instrument description and archived data documentation v1.3, NOAA Technical Memorandum, Space Environ. Lab., Boulder, Colorado

Hayosh M., D. L. Pasmanik, A. G. Demekhov, O. Santolik, M. Parrot and E. E. Titova (2013), Simultaneous observations of quasi-periodic ELF/VLF wave emissions and electron precipitation by DEMETER satellite: A case study, $J$. Geophys. Res., 118, doi:10.1029/jgra.50179.

Helliwell R. A. (1969), Low-frequency waves in the magnetosphere, Rev. Geophys., \%, doi:10.1029/RG007i001p00281.

Hikishima, M., Y. Omura and D. Summers (2010), Microburst precipitation of energetic electrons associated with chorus wave generation, Geophys. Res. Lett., 37, doi:10.1029/2010GL042678.

Horne, R. B., and R. M. Thorne (1998), Potential waves for relativistic electron scattering and stochastic acceleration during magnetic storms, Geophys. Res. Lett., 25, doi:10.1029/98GL01002

Johnston, W. R. and P. C. Anderson (2010), Storm time occurrence of relativistic electron microbursts in relation to the plasmapause, J. Geophys. Res., 115(A02205), doi:10.1029/2009JA014328

Lam M. M., R. B. Horne, N. P. Meredith, S. A. Glauert, T. Moffat-Griffin and J. C. Green (2010), Origin of energetic electron precipitation $>30 \mathrm{keV}$ into the atmosphere., J. Geophys. Res., 115(A00F08), doi:10.1029/2009JA014619.

Lakhina G. S., B. T. Tsurutani, O. P. Verkhoglyadova and J. S. Pickett (2010), Pitch angle transport of electrons due to cyclotron interactions with the coherent chorus subelements, J. Geophys. Res., 115(A00F15), doi:10.1029/2009JA014885.

Li, X., D. N. Baker, T. P. O'Brien, L. Xie, and Q. G. Zong (2006), Correlation between the inner edge of outer radiation belt electrons and the innermost plasmapause location, Geophys. Res. Lett., 33(L14107), doi:10.1029/2006GL026294.

Lichtenberger, L., M. A. Clilverd, B. Heilig, M. Vellante, J. Manninen, C. J. Rodger, A. B. Collier, A. M. Jørgensen, J. Reda, R. H. Holzworth, R. Friedel and M. Simon-Wedlund (2013), The plasmasphere during a space weather event: first results from the PLASMON project, J. Space Weather Space Clim, 3(A23), doi:10.1051/swsc/2013045.
Lyons, L. R., and R. M. Thorne (1973), Equilibrium structure of radiation belt electrons, J. Geophys. Res., 78(13), doi:10.1029/JA078i013p02142

Meredith, N. P., R. B. Horne, D. Summers, R. M. Thorne, R. H. Iles, D. Heynderickx and R. R. Anderson (2002), Evidence for acceleration of outer zone electrons to relativistic energies by whistler mode chorus, Annales Geophysicae, 20, doi:10.5194/angeo-20-967-2002.

Meredith, N. P., R. B. Horne, S. A. Glauert, R. M. Thorne, D. Summers, J. M. Albert, and R. R. Anderson (2006), Energetic outer zone electron loss timescales during low geomagnetic activity, J. Geophys. Res., 111, A05212, doi:10.1029/2005JA011516.

Meredith, N. P., R. B. Horne, M. M. Lam, M. H. Denton, J. E. Borovsky and J. C. Green (2011), Energetic electron precipitation during high-speed solar wind stream driven storms, J. Geophys. Res., 116, A05223, doi:10.1029/2010JA016293

Millan, R. M, K. B. Yando, J. C. Green, and A. Y. Ukhorskiy (2010), Spatial distribution of relativistic electron precipitation during a radiation belt depletion event., Geophys. Res. Lett., 37(L20103), doi:10.1029/2010GL044919.

Newnham, D. A., P. J. Espy, M. A. Clilverd, C. J. Rodger, A. Seppälä, D. J. Maxfield, P. Hartogh, K. Holmén, and R. B. Horne (2011), Direct observations of nitric oxide produced by energetic electron precipitation in the antarctic middle atmosphere, Geophys. Res. Lett., 38(20), L20,104, doi:10.1029/2011GL049199.

O'Brien, T. P., and M. B. Moldwin (2003), Empirical plasmapause models from magnetic indices, Geophys. Res. Lett., 30, 1152, doi:10.1029/2002GL016007.

Rodger, C. J., M. A. Clilverd, N. R. Thomson, R. J. Gamble, A. Seppälä, E. Turunen, N. P. Meredith, M. Parrot, J-A. Sauvaud and J-J Berthelier (2010), Radiation belt electron precipitation into the atmosphere: recovery from a geomagnetic storm, $J$. Geophys. Res., 112, A11307, doi:10.1029/2007JA012383.

Rodger, C. J., M. A. Clilverd, A. Seppälä, N. R. Thomson, R. J. Gamble, M. Parrot, J-A. Sauvaud and T. Ulich (2010), Radiation belt electron precipitation due to geomagnetic storms: significance to middle atmosphere ozone chemistry, J. Geophys. Res., 115, A11320, doi:10.1029/2010JA015599.

Rodger, C. J., M. A. Clilverd, J. Green, and M. Lam (2010), Use of POES SEM2 observations to examine radiation belt dynamics and energetic electron precipitation in to the atmosphere, J. Geophys. Res., 115, doi:10.1029/2008JA014023.

Seppälä, A., H. Lu, M. A. Clilverd, and C. J. Rodger (2013), Geomagnetic activity signatures in wintertime stratosphere wind, temperature and wave response, J. Geophys. Res., 118, doi:10.1002/jgrd50236.

Solomon, S., P. J. Crutzen, and R. G. Roble (1982), Photochemical coupling between the thermosphere and the lower atmosphere: 1. Odd nitrogen from 50 to $120 \mathrm{~km}, J$. Geophys. Res., 87, doi:10.1029/JC087iC09p07206.

Sugiura, M. (1964), Hourly values of the equatorial Dst for IGY, Annals of the International Geophysical Year, 35 (pp945-948), Pergamon Press.

Summers, D., R. M. Thorne, and F. Xiao (1998), Relativistic theory of wave-particle resonant diffusion with application to electron acceleration in the magnetosphere, J. Geophys. Res. 103, A9, doi:10.1029/98JA01740.

Summers, D., B. Ni, and N. P. Meredith (2007), Timescales for radiation belt electron acceleration and loss due to resonant wave-particle interactions: 2. Evaluation for VLF chorus, ELF hiss, and electromagnetic ion cyclotron waves, J. Geophys. Res., 113, A04219, doi:10.1029/2007JA012678.

Summers, D., B. Ni, N. P. Meredith, R. B. Horne, R. M. Thorne, M. B. Moldwin and R. R. Anderson (2008), Electron scattering by whistler-mode ELF hiss in plasmaspheric plumes, J. Geophys. Res., 112, A04207, doi:10.1029/2006JA011993.

Thorne, R. M. (2010), Radiation belt dynamics: The importance of wave-particle interactions, Geophys. Res. Lett., 37(22), doi:10.1029/2010GL044990.

Thorne, R. M., W. Li, B. Ni, Q. Ma, J. Bortnik, D. N Baker, H. E. Spence, G. D. Reeves, M. G. Henderson, C. A. Kletzing, W. S. Kurth, G. B. Hospodarsky, D. Turner and V. Angelopoulos (2013), Evolution and slow decay of an unusual narrow ring of relativistic electrons near $\mathrm{L} \sim 3.2$ following the September 2012 magnetic storm, Geophys. Res. Lett., 40(14), doi:10.1002/grl.50627. 
Turunen, E., P. T. Verronen, A. Seppälä, C. J. Rodger, M. A. Clilverd, J. Tamminen, C. F. Enell, and T. Ulich (2009), Impact of different energies of precipitating particles on nox generation in the middle and upper atmosphere during geomagnetic storms, J. Atmos. Sol. Terr. Phys., 71, 11761189, doi:10.1029/2002GL016513.

Verronen, P. T., C. J. Rodger, M. A. Clilverd, and S. Wang (2011), First evidence of mesospheric hydroxyl response to electron precipitation from the radiation belts, J. Geophys. Res., 116(D07307), doi:10.1029/2010JD014965.

Verronen, P. T., M. Andersson, C. J. Rodger, M. A. Clilverd, S. Wang and E. Turunen (2013), omparison of modeled and observed effects of radiation belt electron precipitation on mesospheric hydroxyl and ozone, J. Geophys. Res., 118, doi:10.1002/jgrd.50845

Whittaker, I. C., R. J. Gamble, C. J. Rodger, M. A. Clilverd and J.-A. Sauvaud (2013), Determining the spectra of radiation belt electron losses: Fitting DEMETER IDP observations for typical and storm-times, J. Geophys. Res., doi:10.1002/2013JA019228

Whittaker, I. C., C. J. Rodger, M. A. Clilverd and J.-A. Sauvaud (2014), The effects and correction of the geometric factor for the POES/MEPED electron flux instrument using a multisatellite comparison, J. Geophys. Res., under review.

Yando, K., R. M. Millan, J. C. Green, and D. S. Evans (2011), A Monte Carlo simulation of the NOAA POES Medium Energy Proton and Electron Detector instrument, J. Geophys. Res., 118, doi:10.1002/jgra.50584

Corresponding author: I. Whittaker, Department of Physics, University of Otago, PO Box 56, Dunedin 9054, New Zealand. (ian.whittaker@otago.ac.nz) 


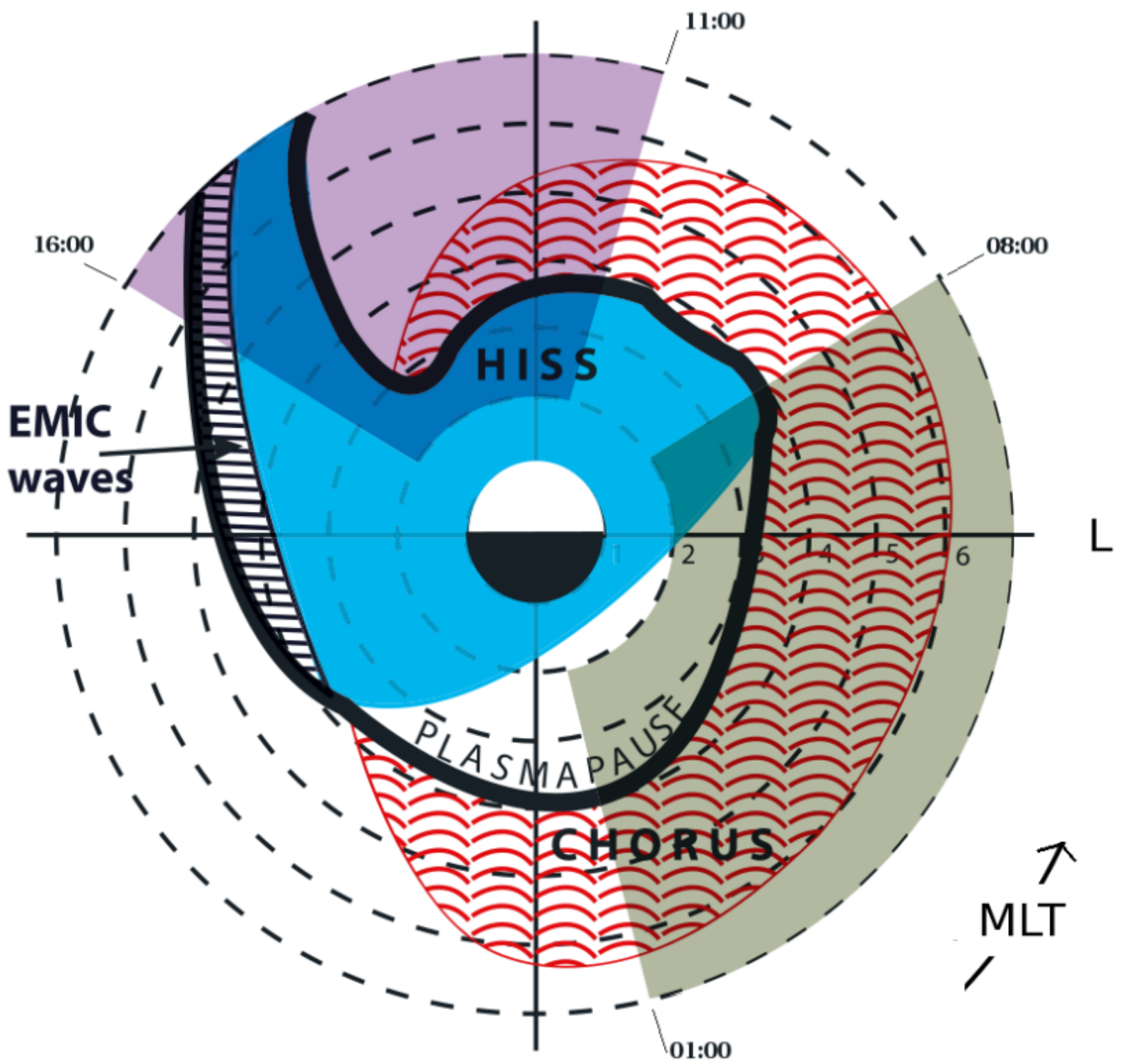

Figure 1: A schematic of the of the wave activity in the radiation belts and plasmasphere adapted from Summers, Ni and Meredith [2007, Figure 21]. The angle from the vertical shows the magnetic local time while the radial distance gives the $L$ shell value. The grey shaded area shows the morning MLT sector that we use in this study to determine the chorus affected zone outside the plasmapause, ranging from 01:00 to 08:00. The purple shaded area shows the afternoon MLT sector which we investigate to determine the plasmapspheric hiss induced fluxes beneath the plasmapause, with an MLT range of 11:00 to 16:00. 

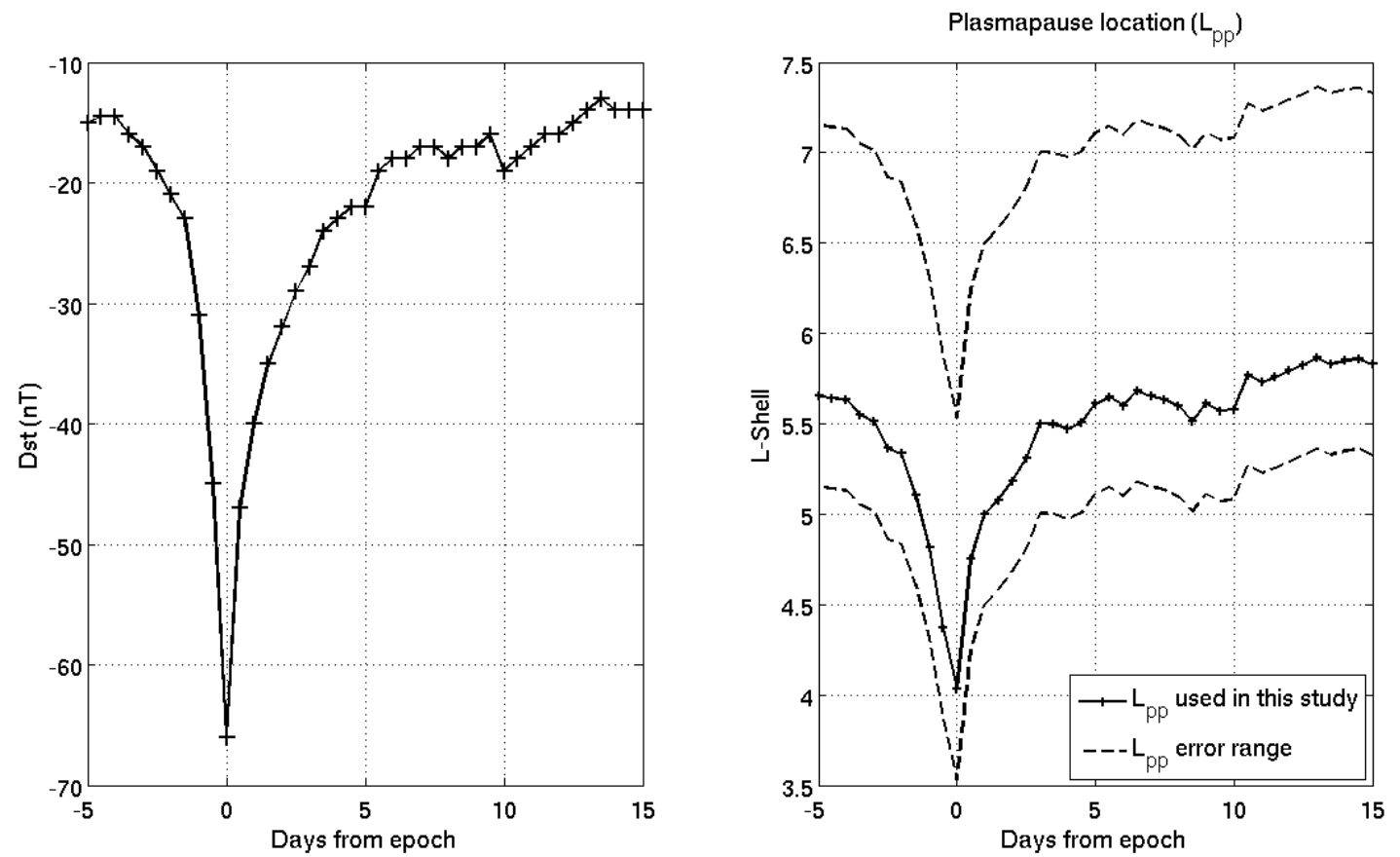

Figure 2: Left: The median Dst values around the 788 geomagnetic storms identified for our superposed epoch analysis, after SPE removal. Right: The variation in the plasmapause location from the superposed epoch analysis using the expression in O'Brien and Moldwin [2003]. The dashed lines show the error range of the model and the solid line indicates the chosen plasmapause location we use for the remainder of this study. The data in both plots is shown in 12 hour resolution to match the electron flux time bins. 

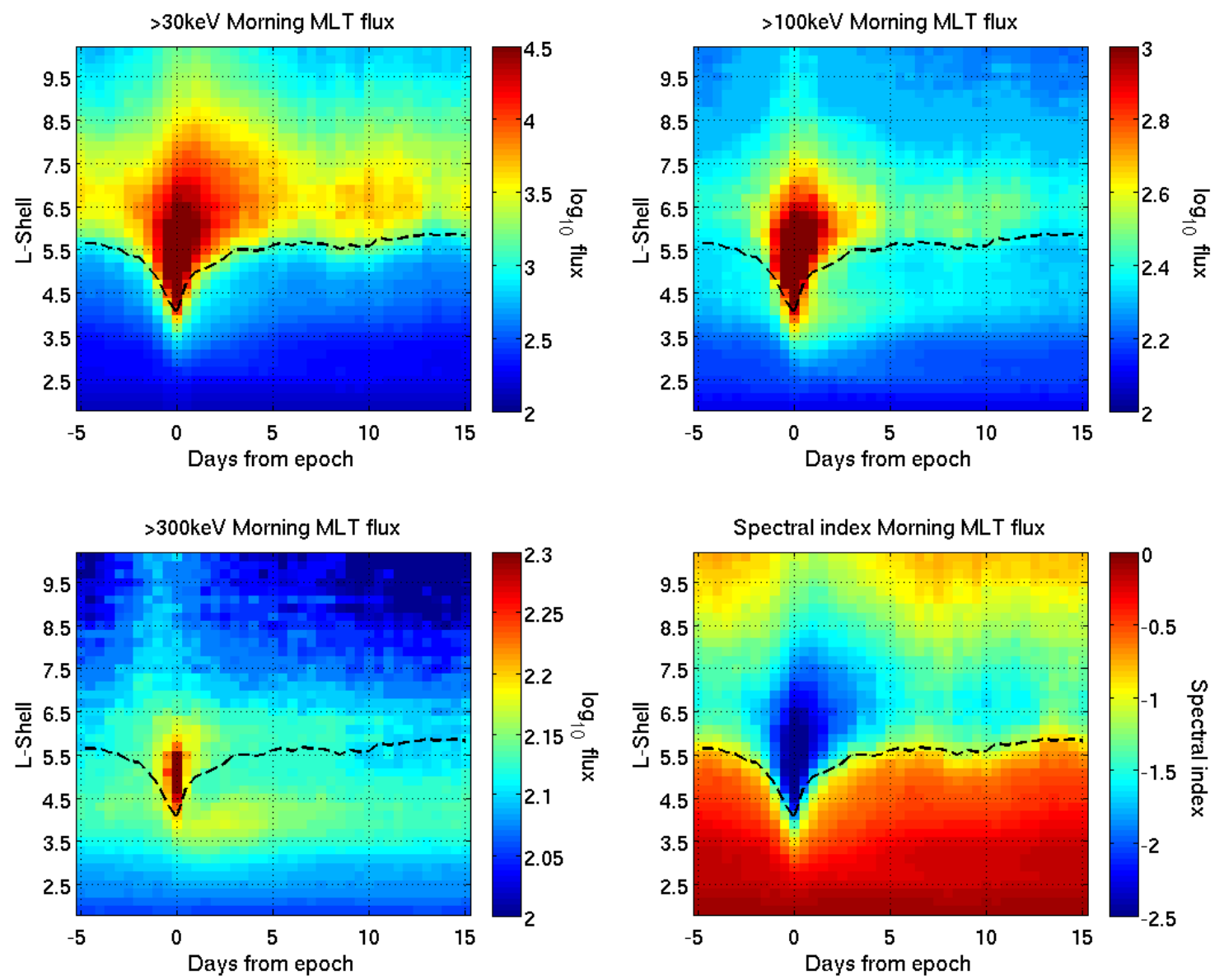

Figure 3: The electron flux variation shown during our superposed epoch analysis for the morning MLT sector 01:00 to 08:00. All precipitating flux panels are shown with units of $e^{-} \mathrm{cm}^{-2} \mathrm{sr}^{-1} \mathrm{~s}^{-1}$. The top left panel shows the median $>30 \mathrm{keV}$ electron flux, the top right panel shows the $>100 \mathrm{keV}$ electron flux and the lower left panel shows the $>300 \mathrm{keV}$ electron flux, all are shown on a $\log _{10}$ color scale. The lower right panel shows the spectral index from a power law fitting of the three energy ranges. The modeled plasmapause location from Figure 2 has been included on all panels as the dashed black line. 

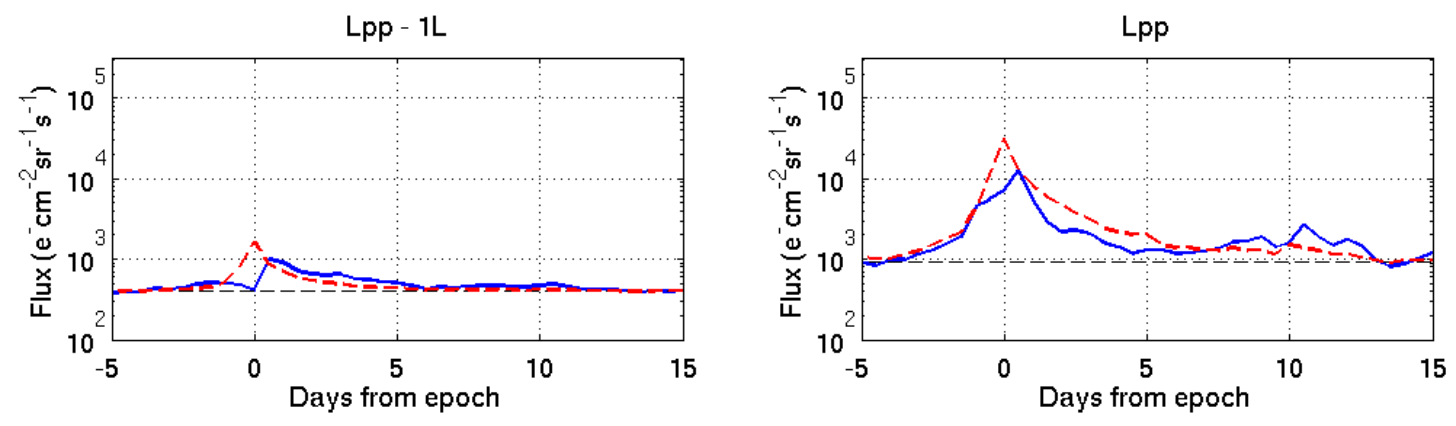

Lpp $+1 \mathrm{~L}$
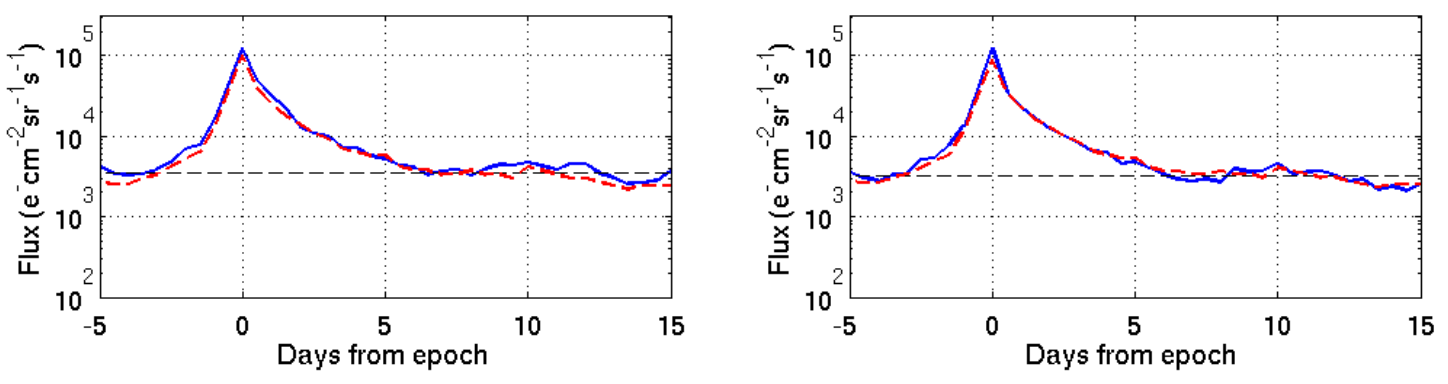

Lpp + 2L
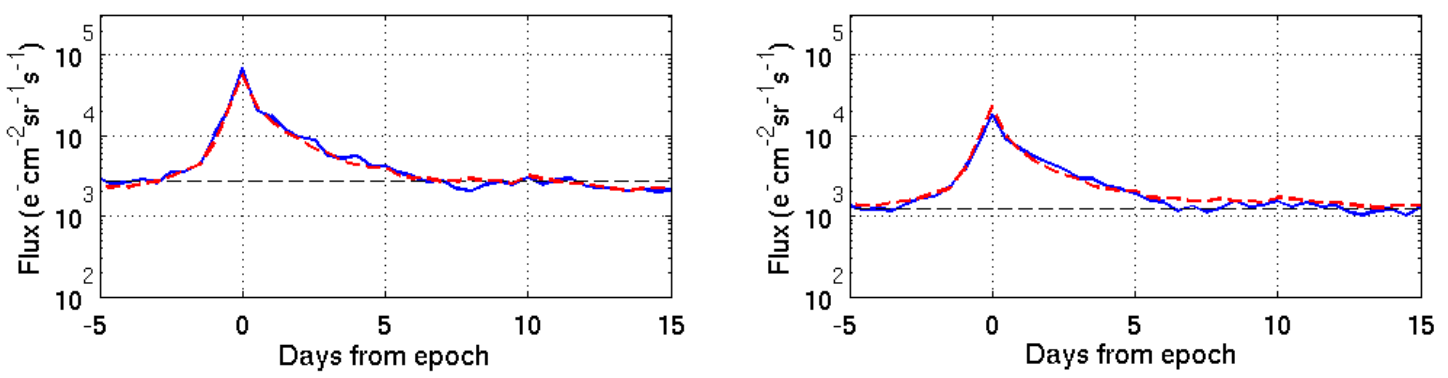

Figure 4: The $>30 \mathrm{keV}$ precipitating electron flux at different distances from the plasmapause $\left(L_{p p}\right)$ are plotted, ranging from $1 L$ (top left panel) inside to $3 L$ outside (lower right panel). The dark blue solid line shows the observed flux after superposed epoch analysis and the red dashed line shows the model flux from Equation (3). 

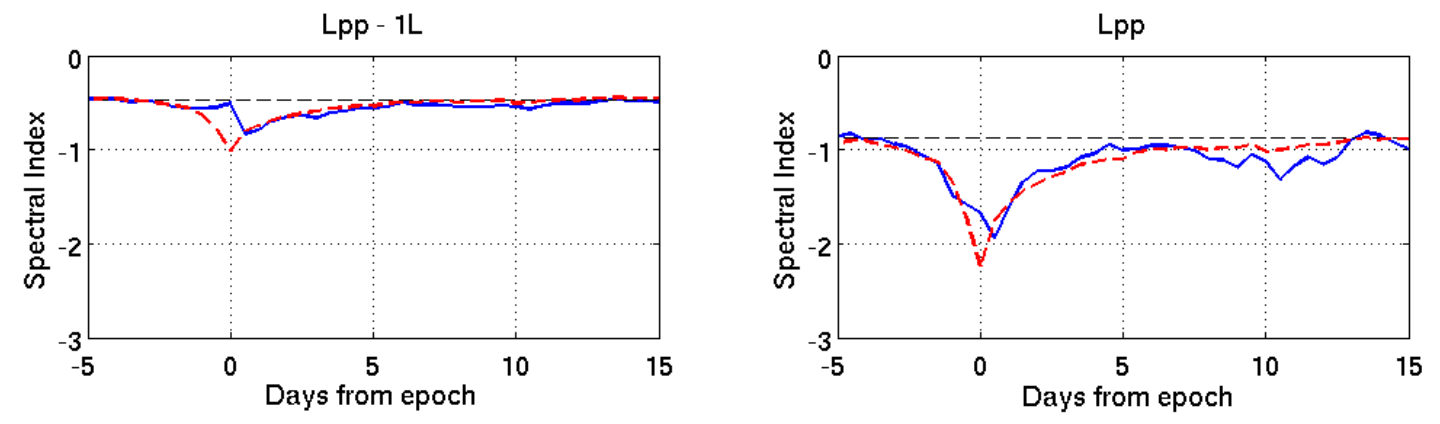

Lpp $+1 \mathrm{~L}$

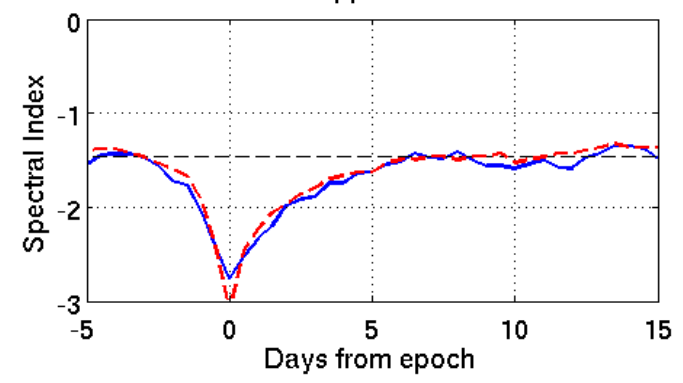

$L p p+1.5 L$

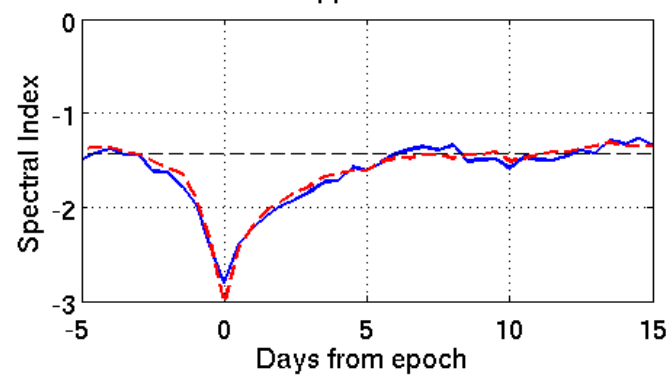

Lpp + 2L
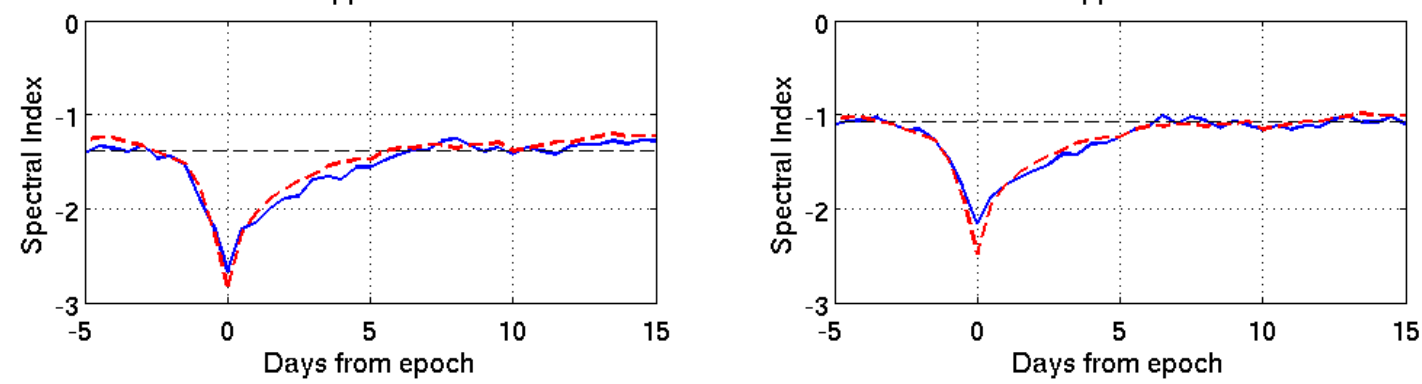

Figure 5: The $>30 \mathrm{keV}$ precipitating electron flux power law spectral index at different distances from the plasmapause $\left(L_{p p}\right)$. Ranging from $1 \mathrm{~L}$ shell inside the plasmapause (top left) to $3 \mathrm{~L}$ shells outside (lower right). The dark blue solid line shows the fitted spectral index and the red dashed line shows the model spectral index from Equation (4). 

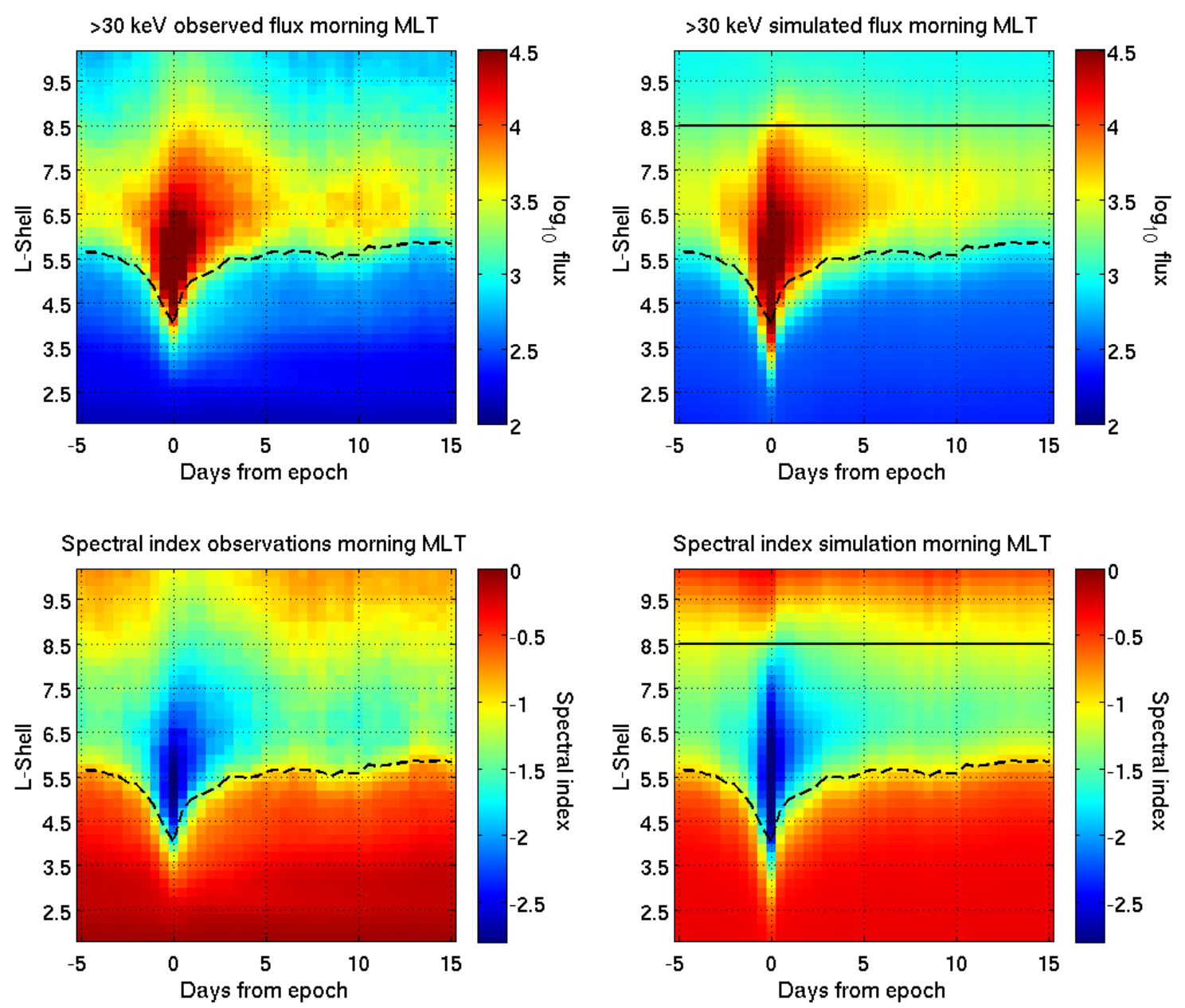

Figure 6: Simulations of the superposed epoch analysis using Equations (3) and (4). The left panels show the experimental observations as seen in Figure 3 and the right panels show the simulations. The top row contains the $>30 \mathrm{keV}$ flux magnitudes and the lower row contains the power law spectral indicies. A solid line has been placed at $L=8.5$ as an indicator of where the model confidence decreases. 

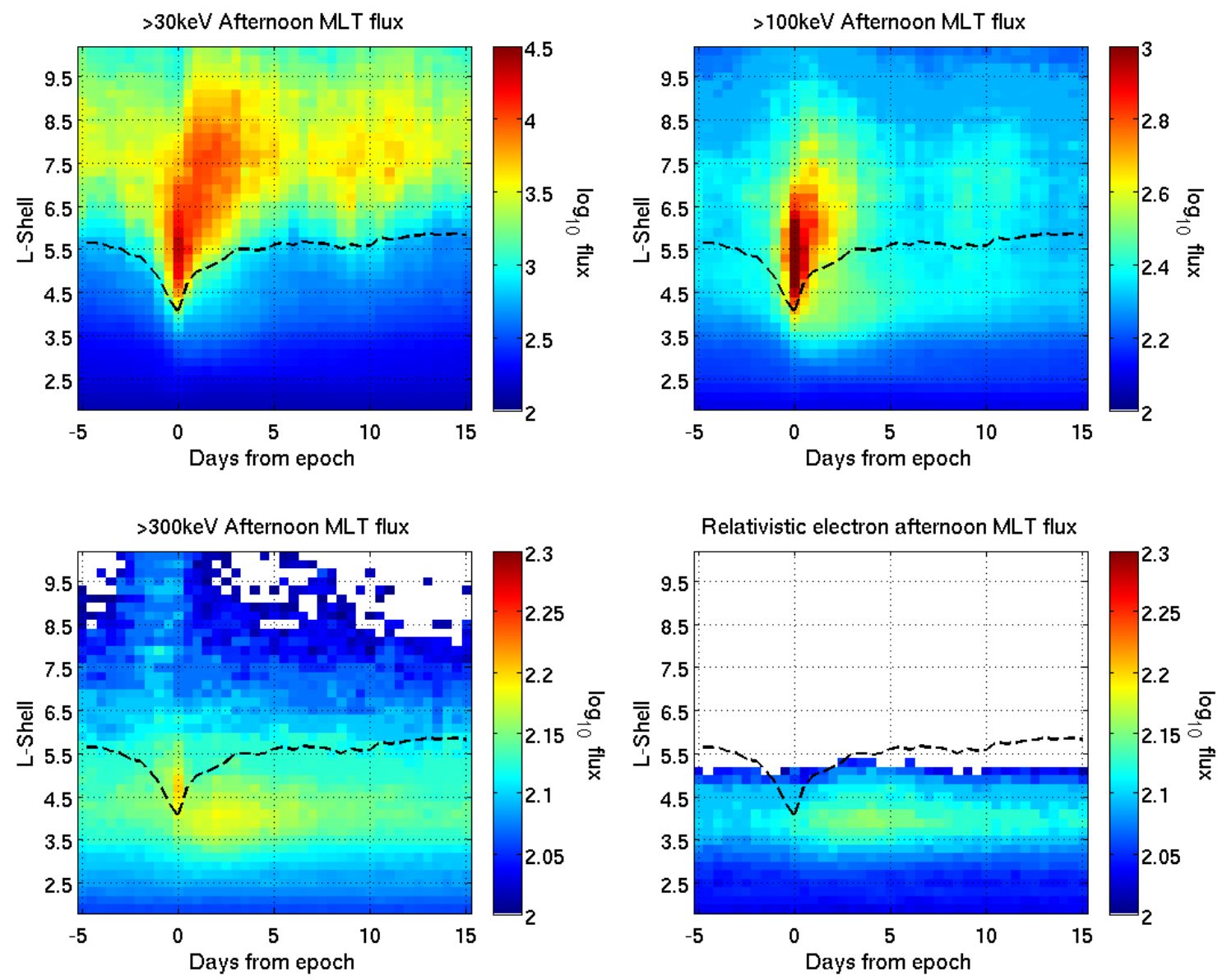

Figure 7: The electron flux epochs for the afternoon MLT sector (11:00 to 16:00). The top left panel shows the median $>30$ $\mathrm{keV}$ electron flux, the top right panel shows the $>100 \mathrm{keV}$ electron flux and the lower left panel shows the $>300 \mathrm{keV}$ electron flux, all are shown on a $\log _{10}$ color scale. The lower right panel shows the P6 MEPED telescope superposed epoch analysis, this telescope includes relativistic electrons with energies $>800 \mathrm{keV}$. The modeled plasmapause location from Figure 2 has been included on all panels as the dashed black line. 

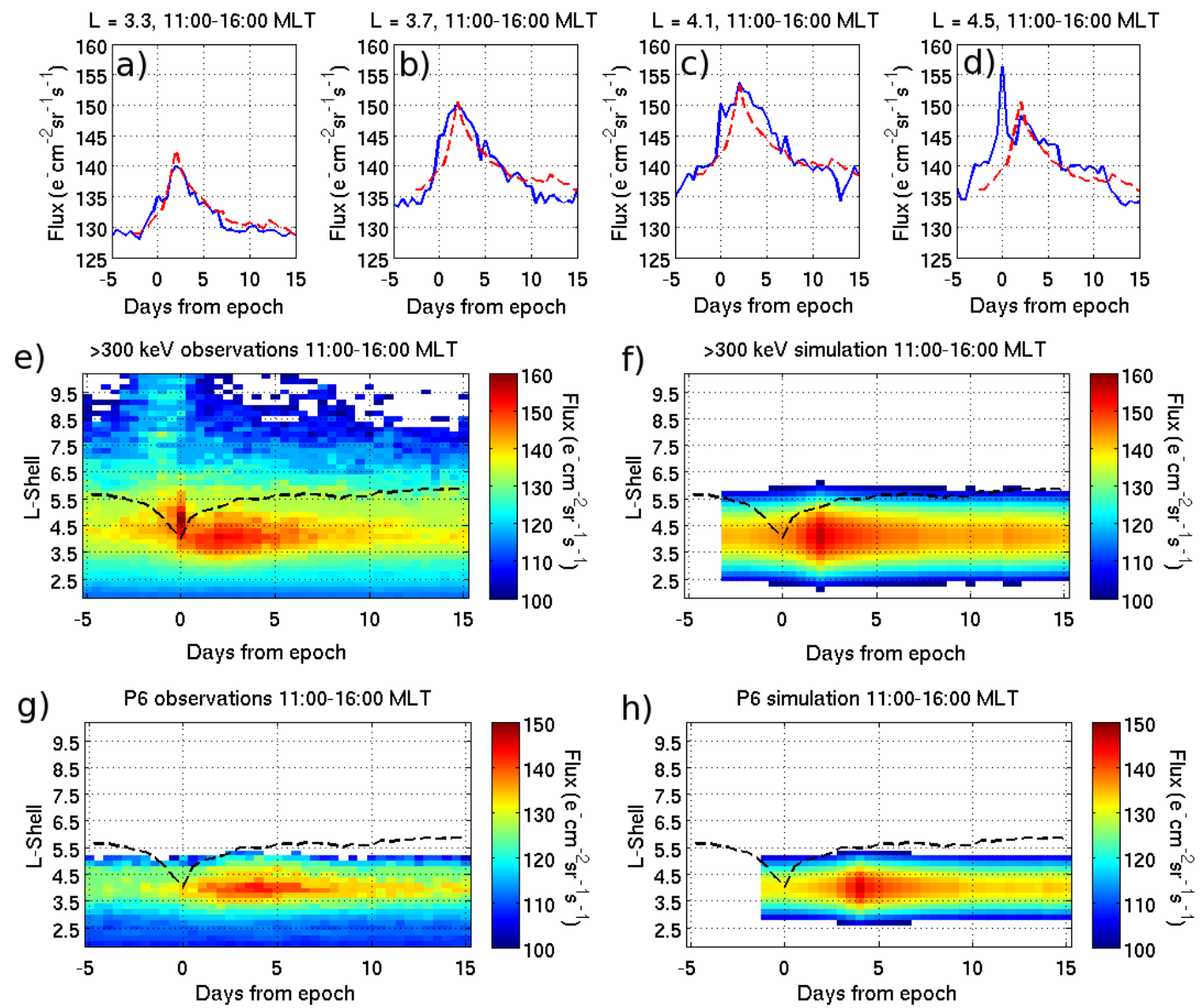

Figure 8: a) to d) The afternoon MLT sector (11:00-16:00) >300 keV electron flux observations at L shells of 3.3, 3.7, 4.1 and 4.5. The solid blue line shows the instrument flux and the red dashed line shows the simulation of the flux at each $L$ shell as calculated by Equation (5). e) The $>300 \mathrm{keV}$ storm epoch from the lower right panel of Figure 7 on a linear color scale emphasising the variation in flux inside the plasmapause by reducing the color range scale. $\mathbf{f})$ The full simulation of the $>300 \mathrm{keV}$ flux inside the plasmapause created using Equation (5), on the same color scale as panel e) and using a 48 hour lag in Dst. g) shows the P6 observations from the lower right panel of Figure 7 on a linear color scale. $\mathbf{h})$ The P6 simulation generated from Equation (6), on the same linear color scale as panel g) working on a 96 hour Dst delay. The black dashed line in the epoch plots is the modeled plasmapause from Figure 2. 

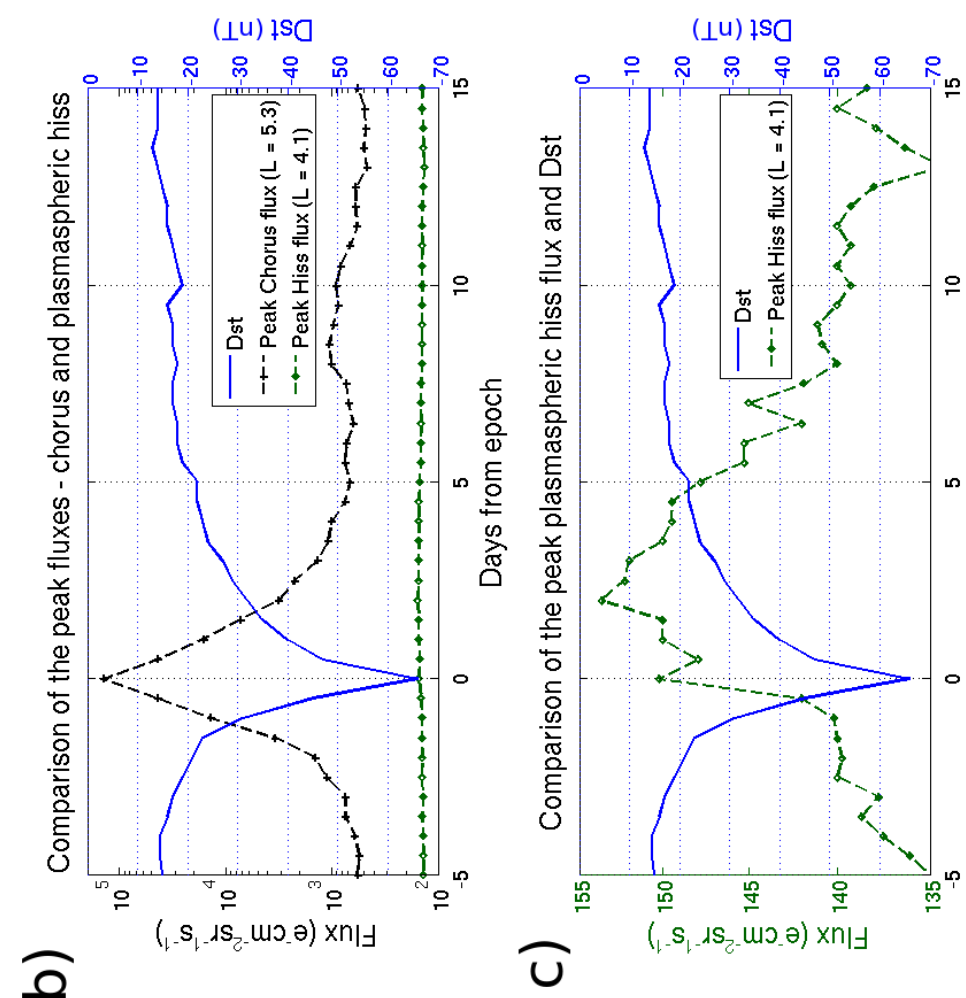

E. 웡

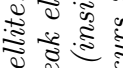

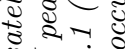

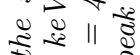

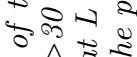
ชิ

है है है हैं

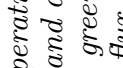
के क्स ह

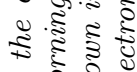
हू हो का 苾离 है है ह है. 20

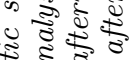

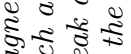

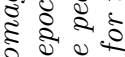
\&े $)$ उె हิ ए) - की उั र ป ริ ธี

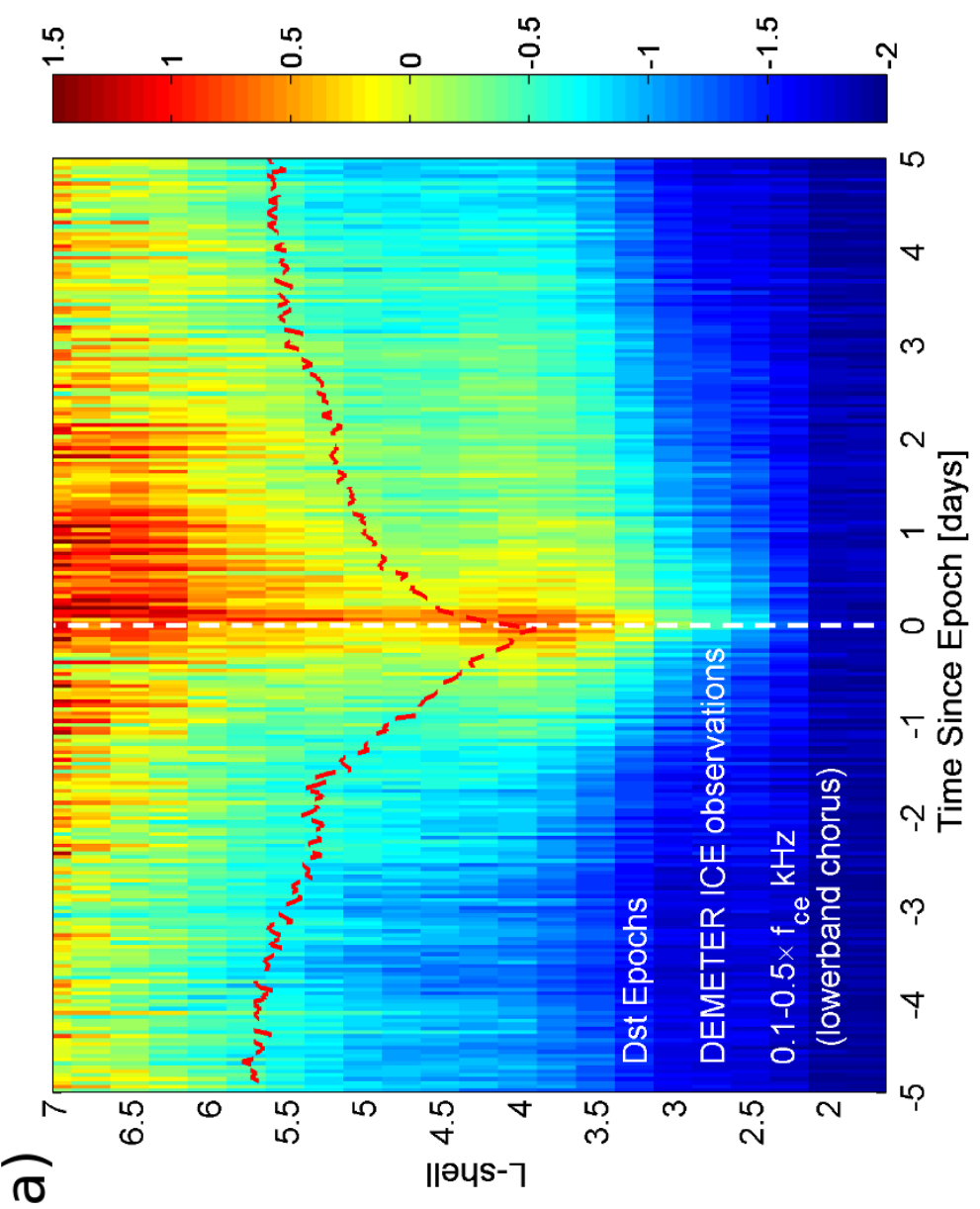

